\title{
EXPERIMENTAL STUDY ON VISUAL SENSATION BY ELECTRIC STIMULATION OF THE OPTIC NERVE IN MAN*
}

\author{
BY \\ JUNICHI NAKAGAWA \\ Ophthalmological Department, Sapporo Municipal Hospital, Sapparo, Japan
}

NuMERous reports have been published of the effects of optic nerve stimulation upon neuronal mechanisms of the brain in animals, but little work seems to have been done in man.

In the present experiment, therefore, an attempt has been made to investigate the effects of optic nerve stimulation upon visual sensation in a conscious patient.

\section{Case Report}

A man aged 38, an architect by profession, had been admitted to the surgical department in this hospital with the diagnosis of right maxillary carcinoma, and a radical right upper jaw bone removal was made in March, 1945. During this operation the patient's lower eyelid was resected. The recovery was favourable but he began to suffer with ocular pain, and was admitted to the ophthalmological clinic on November 8, 1945.

Examination.-He was of medium stature, nutrition excellent, judgment clear, memory and introspection good, and answered all questions clearly.

The visual acuity in each eye was $1 \cdot 2$ (n.c.), visual fields and fundi normal. A colour blindness check by Ishihara's chart revealed deuteranopia.

The site of operation showed removal of the right upper jaw bone and part of the cheek bone. The lower fringe and lower floor of the orbit were missing, forming a deep funnel-shaped cavity extending to the pharynx and nasal cavity. The right eyeball was exposed in the lower part and was covered by mucous membrane and granulated tissue. The side and lower walls of the cavity were covered by a curling-in of the skin of the cheek. The eyeball hung downwards because it was unsupported by the lower orbital wall, but there was no obvious hindrance to the eye movements. The lower half of the cornea was exposed, and small half-moon ulcerations were seen along the lower portion of the corneal limbus. The ulcers were shallow with no hypopyon, and the rest of cornea was clear. The conjunctiva adjacent to the ulcers showed slight hyperaemia. There were no other abnormalities.

Treatment.-To preserve the eyeball a plastic operation of the cornea was conducted. The grafted bridge-type conjunctival graft stayed in place for one day and then became detached, giving rise to new ulcerations. The patient complained of a recurrence of pain and at his request the eyeball was removed on November 30 .

This enucleation enabled the following experiment to be carried out using

\footnotetext{
* Received for publication October 23, 1961.
} 
a Faradic current of 160 per second frequency from an inductorium (Muto Co. common type). The strength of the current could be changed by varying the coil distance and by turning the dial set on the board. A pair of platinum wires $0.5 \mathrm{~mm}$. in diameter and $1.7 \mathrm{~mm}$. apart were used as the electrode for stimulation.

At the time of the operation the optic nerve was severed directly behind the eyeball, and in order to make manipulation easier, a $10 \mathrm{~mm}$. length of suture was tied lightly to the nerve and secured. This was done in order to avoid needless mechanical stimulus by tweezers which would otherwise have been necessary to hold the nerve in place at the time of stimulation. The optic nerve was sufficiently ablated from the surrounding fat tissue, and covered with Vaseline-coated gauze in preparation for the experiments to be conducted the following day.

The stimulation experiments were conducted 24 hours after the removal of the eyeball. The patient was placed on the operation table without previous notice, in order to ensure his peace of mind. A 100-watt bulb was suspended at approximately $50 \mathrm{~cm}$. above the operation table and switched on. The room was facing south and was full of light, the time being 2 p.m. The healthy eye was closed and covered with a white cloth. The operated eye was opened and the inserted gauze was removed. The patient complained of pain so a drop of 4 per cent. cocaine solution was administered to the site of adhesion. Special care was taken not to touch the optic nerve. The eye socket was washed and the Vaseline removed and at the same time efforts were made to remove the anaesthetic solution. Lastly the washing fluid was carefully absorbed by the application of surgical cotton and the optic nerve was lifted clear of its surroundings by means of the string attached previously. Special care was taken to prevent any leakage of electric current through fluids and surrounding tissue.

The cut surface of the optic nerve was held horizontally and the electrode was placed gently on the cut surface. Since the electrode was smaller in size it was possible to move it to different positions on the cut surface of the optic nerve.

\section{Results}

(1) Effects of Electrical Stimulation.-The strength of the stimulus was heightened in an ascending curve. First the coil distance was set at $8 \mathrm{~mm}$. and the first response was obtained when the dial reading was turned to 21 . Next the dial was turned to 24 .

As a second step the distance was reduced to $7 \mathrm{~mm}$. and the dial turned up.

As a third step the distance was reduced to $6 \mathrm{~mm}$. This was the strongest stimulus rendered.

It was found that at the same coil distance the dial reading increased systematically, but it was impossible to compare the dial readings at different 
coil distances. The results are shown in the Table in the order of the experiments and in the diagrams (Figs 1-4, opposite).

TABLE

\begin{tabular}{|c|c|c|c|}
\hline $\begin{array}{l}\text { Coil } \\
\text { Distance }\end{array}$ & $\begin{array}{c}\text { Dial } \\
\text { Reading }\end{array}$ & $\begin{array}{l}\text { Subject's Own } \\
\text { Words }\end{array}$ & Explanations given by Subject the next day \\
\hline \multirow[t]{2}{*}{8} & 21 & "I saw something!" & $\begin{array}{l}\text { He sensed a whitish something which he } \\
\text { could not describe. }\end{array}$ \\
\hline & 24 & "Stick-like" & $\begin{array}{l}\text { Parallel lines (Fig. 1), } 5 \text { or } 6 \text { in number. } \\
\text { Length 2-3 mm. Red and white } \\
\text { alternating. }\end{array}$ \\
\hline \multirow[t]{7}{*}{7} & 11 & "Diamond-shaped" & $\begin{array}{l}\text { (Fig. 2) Red and white alternating, } \\
\text { Size } 1.5 \mathrm{~mm} \text {. }\end{array}$ \\
\hline & 13 & "Petal pattern" & $\begin{array}{l}\text { Radiating lines (Fig. 3). White, red and } \\
\text { violet alternating. The lines sparkled. }\end{array}$ \\
\hline & $\begin{array}{l}14 \\
14 \cdot 3\end{array}$ & $\begin{array}{l}\text { "Blue and red sensation" } \\
\text { "White sensation" }\end{array}$ & Disappeared immediately. \\
\hline & $\begin{array}{l}16 \\
16 \cdot 3\end{array}$ & $\begin{array}{l}\text { "Violet-no shape" } \\
\text { "Dim light" } \\
\text { "Shell-shaped" }\end{array}$ & $\begin{array}{l}\text { (Fig. 4). He reported a white sea-shell } \\
\text { shape, with numerous glass bead-like or } \\
\text { dewdrop-like sparkling things decorating } \\
\text { the upper part. The centre had a } \\
\text { violet hue. }\end{array}$ \\
\hline & 18 & "Bright appearance" & $\begin{array}{l}\text { This was seen in the centre part, and also } \\
\text { in upper and lower areas. It changed. }\end{array}$ \\
\hline & 19 & "Violet" & $\begin{array}{l}\text { This was divided in two on the right side } \\
\text { and the centre part over to the right side. }\end{array}$ \\
\hline & 23 & "Sickle-shaped moon" & $\begin{array}{l}\text { This was seen brightly and clearly. The } \\
\text { brightness can be described as equivalent } \\
\text { to dawn light seen through a board knot } \\
\text { from the dark interior of a house. } \\
\text { This gradually disappeared. }\end{array}$ \\
\hline \multirow[t]{2}{*}{6} & 15 & $\begin{array}{l}\text { "Rapid blinking off } \\
\text { and on" }\end{array}$ & \\
\hline & 20 & $\begin{array}{l}\text { "I am tired" } \\
\text { "It hurts" }\end{array}$ & \\
\hline
\end{tabular}

The sensation of light occurs simultaneously with the onset of the stimulus. It appears suddenly. It disappears as soon as the stimulus is stopped, but when the stimulus is continued the sensation gradually dims and disappears. The duration of sensation varies, but when a shape is sensed there is sufficient time to determine the shape. When the patient was asked for an answer, his response was, "Wait a minute please." "I've got it now. It's ...." This happened quite frequently. The duration was at least 2 to 3 seconds, and the longest duration reported by the patient was about 5 seconds. It was noted that when the stimulus was repeated under the same conditions an 
I

3
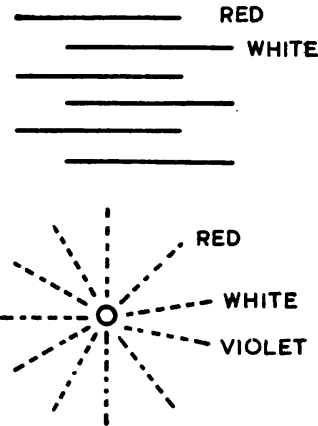

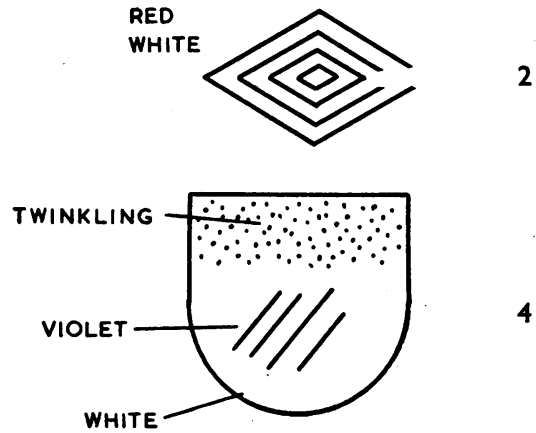

WHITE

FIGURE.-Four examples of visual sensation as described by the subjects.

approximately similar sensation appeared. The significance of this lies in the determination of reproducibility, and at the same time it indicates that the excitability of nerves (including the optical centre) recovers to normal in a very short time.

The sensation of light, according to the patient, appeared in complete darkness in the form of electric sparks, fireworks, or dewdrops reflecting light and sparkling. At times the sensation was a mere sense of presence of light, at others, it was a brightness with a given shape (e.g. a sickle-moon), and at others it was whiteness. Colours were seen, but only red, blue, and violet, without green, yellow, etc. It is to be noted that the patient had green blindness.

Since an electric light was suspended overhead, the healthy eye experienced an even sense of light in its visual field when no stimulus was applied. However, it was noted that, when a sense of light was induced by stimulation as described, the patient reported brightness against a dark field, indicating that there was no relationship between the severed nerve and the vision of the other eye. The patient mentioned that the sensations of light were the same whether he opened or closed his healthy eye.

The sensation of light appeared at times at the centre of vision and at times at the periphery. Sometimes with a single stimulus, the sensations appeared in two different areas of the vision. In the case of clearly-defined light sensations, the position and direction could be clearly indicated, but in other cases when the patient reported "a feeling of light" the position and direction were not clear.

When the image was formed at the centre of the vision, the shape was clear, but when the images appeared at the periphery the shape was indefinable. An interesting point is that when the tip of a diamond shape was outside the centre of vision, only the tip appeared blurred. It was noted that colour appeared not only in the centre but also on the fringes.

The identified simple shapes were one- or two-dimensional and were of the opposing symmetrical type. The most complicated shape was the sea-shell. 
It was also noted that not infrequently white, red, and at times purple coexisted in a single shape.

The site of stimulation in the majority of cases was approximately at the centre of the severed surface. The corresponding sensations appeared at the centre or the periphery with no definite pattern. Since the severed point was directly behind the eyeball, fibres from the macula lutea should be on the temporal side of the severed surface. Therefore stimulation in the central area does not necessarily imply stimulation of the macular fibres. The site of stimulus was varied in order to determine corresponding light sensation areas in the field of vision, but no definite pattern was seen. Whether this was due to the comparatively large size of the electrode in comparison with that of the severed surface or to other factors is not known.

In regard to the strength of stimulus and the colour, it was shown that a very weak stimulus gave a sensation merely of brightness, and a medium stimulation usually caused a brightness with colour or a sparkling with colour to be seen in addition to the brightness or whiteness. However, there was no definite relationship between the strength of stimulation and the colour pattern. With a weak stimulus shapes were not clear, but with a medium stimulus they became clearer. Generally the intensity of the sensations increased with the increase in stimulus, but beyond a certain point a strong stimulus does not produce a sensation of light but brings on a feeling of fatigue and pain.

(2) Effects of Mechanical Stimulation.-No systematic experiments using mechanical stimuli were conducted, but when the electrode stimulus tests were concluded and the string attached to the optic nerve was about to be removed, the string was held up slightly pulling up the optic nerve. Then the optic nerve was severed with surgical scissors in a single motion. Thus, we were able to obtain the following information, which was entirely unintentional. The patient then suddenly exclaimed that he had seen something and stated that it was as if a white cloud had passed in front of his eyes. We believe that this may be considered as a light sensation resulting from a mechanical stimulus; in this case the severing of the nerve. It was lastly noted with interest that the reaction was identical to that of the contraction of the muscle when the nerve attached to a muscle is severed.

\section{Summary}

Experiments were conducted on a middle-aged male, who apart from green-blindness, had healthy visual organs.

It was clearly demonstrated that when the optic nerve was directly stimulated with faradic current, a visual sensation occurred. Under certain given conditions the sensation of light was accompanied by colours, in addition to brightness with a definite shape, and position or direction in the visual field. When the stimulus was applied again the same light sensations recurred. The duration of the sensations did not exceed 4 to 5 seconds. 